\title{
Abdomen agudo ni médico ni quirúrgico. Reflexiones sobre la medicina basada en evidencias
}

\author{
Jaime Duclos $\mathrm{H}^{1}$. \\ Acute abdominal pain of difficult \\ diagnosis. Report of one case \\ and reflections about \\ evidence based medicine
}

Evidence based medicine is strongly positioned in medical practice. However we must remember that it should be just a part of our knowledge and skills and that a close relationship with our patients is essential. I report a 52 years old male that presented with abdominal pain in the right upper quadrant lasting seven days, that started after participating in a celebration dinner. Abdominal ultrasound was normal and biochemical tests were within normal limits. An upper gastrointestinal endoscopy showed a toothpick that was perforating the gastric wall. The toothpick was withdrawn and the pain subsided. The patient was discharged asymptomatic three days later (Rev Méd Chile 2006; 134: 1197-99).

(Key words: Abdominal pain; Evidence-based medicine; Foreign-body reaction)

Recibido el 19 de mayo, 2006. Aceptado el 24 de mayo, 2006.

${ }^{1}$ Escuela de Medicina, Universidad de Valparaíso. Servicio de Medicina, Hospital Naval «Almirante Nef», Viña del Mar, Chile.

$\mathrm{E}^{\mathrm{n}}$ abril de 2006 me tocó enfrentar la siguiente situación clínica en mi turno de Residencia: un hombre de 52 años había ingresado por dolor abdominal, iniciado siete días antes, luego de una celebración. El dolor se situaba en el hipocondrio derecho, con carácter cólico, intenso y de preferencia posprandial. Había concurrido en dos ocasiones al servicio de urgencia, recibiendo antiespasmódicos e indicación de realizarse una ecotomografía abdominal la que no se había

Correspondencia a: Dr. Jaime Duclos Hertzer. Avenida Coraceros 50, Condominio Mare Nostrum, Depto. 161, Viña del Mar. Fax: (32) 687472. E mail: jduclos@vtr.net logrado hacer. El día anterior lo había visto en policlínico con un becado de medicina interna. El paciente seguía con mucho dolor y se había agregado resistencia muscular. No estaba ictérico ni relataba coluria. «Caso fácil, pensé: envíalo al Servicio de Urgencia con diagnóstico presuntivo de cólico biliar complicado y iya estál». A las 20:00 $\mathrm{h}$ del día de mi turno me llamaron por el paciente: estaba con dolor muy intenso, había resistencia muscular involuntaria y Blumberg esbozado en todo el hemiabdomen superior. Estaba, además, sudoroso, hipotenso y con sensación nauseosa. «ácil, pensé, abdomen quirúrgico» Mientras pedía la ecotomografía abdominal (que se había realizado en la mañana) para verla y asegurar el 
diagnóstico de colelitiasis complicada, solicité exámenes de protombina, TTPK y ECG para cooperar con el cirujano. Me incomodó mucho ver que toda la bioquímica era normal iY también la ecotomografía! Pese a que el colega radiólogo que había realizado el examen era muy experto, pensé que todos nos podíamos equivocar y llevé al paciente a la sala de escáner para realizarle un estudio de abdomen, en primera instancia sin medio de contraste iv. En el intertanto el paciente estaba muy apremiado, seguía hipotenso, sudoroso y me pedía por favor que hiciera algo por él. Recibía hasta el momento solución salida isotónica a $200 \mathrm{ml} / \mathrm{h}$ iv, oxígeno y había iniciado un tratamiento antibiótico empírico. Pero el más apremiado era yo: veía que el paciente se estaba agravando rápidamente y que podría eventualmente morir. El escáner, para mi angustia y «disgusto»fue normal. Rápidamente ordené que se le inyectara medio de contraste pues tal gravedad solo podría reflejar algún problema vascular. ¡Nada! Todo normal. Yo soy habitualmente calmado para manejar cualquier situación clínica pero en ese momento confieso que estaba muy afligido. Se me pasaban por la mente todas las posibilidades de abdomen agudo no quirúrgico: crisis addisoniana, porfiria, fiebre del mediterráneo, etc. Pero no tenía ninguna orientación en ese momento. Le pregunté mil veces por antecedentes de dolor abdominal previo, ingesta de antiinflamatorios, pirosis, pero no; había sido siempre un hombre sano. Corriendo fui a solicitarle a un colega gastroenterólogo que afortunadamente hacia guardia en la Unidad de Cuidados Intensivos que le hiciera a mi enfermo una endoscopia alta, sin tener idea de lo que podría encontrar: un «mondadientes» de siete $\mathrm{cm}$ de largo había atravesado la pared gástrica en sus dos tercios. Hábilmente mi colega pudo extraerlo, tomándolo de los dos últimos $\mathrm{cm}$ que asomaban aún en el sitio de la perforación (tengo fotos del «mondadientes» y la videoscopia para quienes tengan interés en verlas). El alivio del paciente fue inmediato y se fue del hospital sonriente, al tercer día del procedimiento. Desde entonces prometí nunca beber un Martini con aceitunas ensartadas en mondadientes.

En su magnífica conferencia de incorporación a la Academia Chilena de Medicina, en octubre de 2005, el Dr. José Adolfo Rodríguez Portales ${ }^{1}$ hizo un periplo epistemológico del desarrollo del pensar en medicina y presentó casos clínicos vividos por él, muy interesantes y dramáticos. Afirmó que la medicina se ha ido complicando mucho más allá que la mera descripción de casos clínicos singulares y la «ciencia»se ha ido incorporando a la medicina de manera vertiginosa. El se sustenta en Galeno, quien ya en el siglo II decía que «una cosa vista una sola vez no puede ser tomada por cierta, ni siquiera lo que ha sido visto unas pocas veces». ¿Es que acaso yo hice ciencia con mi enfermo? ¿Podría Galeno preguntarle a mi paciente si fue verdad y cierto lo que vivió y sintió? Si hubo algo positivo en este caso, desde el punto de vista de acción médica, es el hecho de haber estado al lado del enfermo y haber empleado juicio y criterio: mi paciente tenía algo grave y debía seguir caminos y razonamientos no tradicionales» para poder hacer el diagnóstico. A este caso lo denominé «abdomen agudo endoscópico» $\mathrm{y}$, con el perdón de Galeno, para mí fue muy cierto y nunca lo podré olvidar. Figura desde entonces entre mis diagnósticos diferenciales de «abdómenes agudos raros».

Me preguntaba cómo reaccionaría frente a este caso un médico del año 2030 en que toda su experiencia y formación podría estar basada en las verdades dogmáticas e inflexibles de los ensayos clínicos randomizados y metaanálisis ¿Cuántos estudios de clase uno «o superior»existirían para aquel tiempo, que comparasen dos poblaciones con al menos cien personas, una con mondadientes atravesando la pared gástrica y la otra con mondadientes - placebo?

Estamos llegando ahora al momento en que algunos piensan que la verdad de un trabajo randomizado, prospectivo, doble ciego (lo «op» de la Medicina Basada en la Evidencia - MBE) es verdad siempre cuando me guste a mí».

Ross y $\operatorname{cols}^{2}$ en un magnífico trabajo que cumplía todos los requisitos de excelencia según la MBE «borró el dogma» de que el reemplazo hormonal en hipotiroideos no cardiópatas debería empezarse en forma gradual, como señalan textos clásicos de medicina. No, el comenzó con dosis plenas desde un comienzo y no tuvo contratiempos con sus enfermos. Pues bien, al Dr. Wartofsky, Master del American College of Physicians en una Editorial de Arch Intern $\mathrm{Med}^{3}$ no le gustó el artículo»y lo consideró poco prudente, insinuan- 
do que ojalá los médicos se olvidaran de él. Sí lo encontró «nteresante», que es una acepción muy académica para decir que lo dicho o hecho mejor no hubiese sucedido.

Diskin 4 , en una genial respuesta, replica que el trabajo de Ross no es anecdótico sino que un estudio serio y cuyos resultados deberían ser incorporados como parte de nuestro conocimiento. Agrega que las sacciones médicas no deben ser monolíticas» y que hoy las prácticas de hacer medicina según pautas o normas dictadas por la MBE son a menudo conflictivas y causan problemas a los pacientes. Nos recuerda a Osler, quien decía que las decisiones médicas deben ser individualizadas y tomadas al lado de la cama del paciente.

\section{REFERENCIAS}

1. Rodríguez JA. Del caso clínico al metaanálisis: evolución de la epistemología médica. Bol Acad Chil Med 2005; 55-67.

2. Ross A, Lunn-Rajken SP, van Damburg RT, Tissen JP, BERG HOUT A. The starting dose of levothyroxine in primary hypothyroidism treatment: a prospec-
Sabiamente el Dr. Rodríguez, en las conclusiones de su conferencia, comenta que no estará lejos el día en que el péndulo de la epistemología médica nos grite: «Volved al paciente! La medicina es demasiado compleja para reducirla a cálculos matemáticos».

Cuando enferme gravemente, que Dios me otorgué en su bondad «algo bueno», quiero que me escuchen y conversen, no que me sapretujen» en algún «rial»para ofrecerme alguna alternativa terapéutica. Quiero a mi lado a un médico que crea lo que siento, aunque fuese la primera vez que le toque experimentarlo.

No hay MBE capaz de comparar los beneficios de morir de una u otra manera.

tive, randomized, double-blind trial. Arch Intern Med 2005; 185: 1714-20.

3. WARTOFSKY L Levothyroxine theraphy for hypothyroidism. Should we abandon conservative dosage titration? Arch Intern Med 2005; 165: 1683-84.

4. Diskin $\mathrm{CH}$. A change of reason: Medicine and the scientific revolution. Letter. Arch Intern Med 2006; 166: 369-70. 